\title{
110. Further Evidence for the New Structure of Violanin as Revealed by Degradation with Hydrogen Peroxide
}

\author{
Studies on Anthocyanins. XLI*) \\ By Kôsaku TAKeda and Kôzô HaYAShI \\ Botanical Institute, Faculty of Science, Tokyo University of Education \\ (Comm. by Yuji Shibata, M.J.A., Sept. 12, 1963)
}

In the preceding papers ${ }^{1,2)}$ of this series, it was stated that violanin, the well known anthocyanin of deep violet pansy, is an acylated triglycoside of delphinidin, in which D-glucose $(2 \mathrm{mols}$.$) , L-$ rhamnose $(1 \mathrm{~mol}$.$) and p$-coumaric acid $(1 \mathrm{~mol}$.) are involved in glycosidation, and that two molecules of glucose are combined separately with 3- and 5-hydroxyl groups of delphinidin. However, the position of attachment of organic acid and rhamnose has not been determined as yet. Fortunately, this was achieved by the application of the method of oxidative degradation with hydrogen peroxide, that was previously shown by P. Karrer and G. de Meuron ${ }^{3)}$ to be specific for the detection of sugar(s) attached to the 3-hydroxyl group of anthocyanins. Moreover, an important clue as to the position of organic acid attachment may also be provided by this method, when carefully applied in combination with paper chromatographic examination of the degradation products.

By treatment with hydrogen peroxide, violanin gave L-rhamnosylD-glucose acylated with $p$-coumaric acid as one of the degradation products; this was easily detectable on the paper chromatogram not only by its blue fluorescence under ultra violet light in the presence of fuming ammonia but also by visible spots developed with either of the reagents such as diazotized sulfanilic acid, aniline hydrochloride, and silver nitrate. Moreover, it was shown that this acylated sugar complex gave, after controlled acid hydrolysis, $p$-coumaroyl-L-rhamnose as an intermediate together with $p$-coumaric acid, D-glucose, and L-rhamnose.

From these facts, it becomes evident that in violanin the 3-hydrooxyl group of delphinidin is occupied by $p$-coumaroyl-L-rhamnosyl-D-

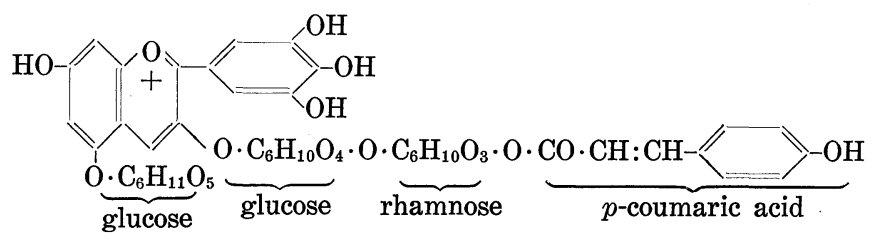

*) Part XL: Bot. Mag. Tokyo, 76, 206 (1963). 
glucose and, therefore, the total structure of violanin should be expressed by the formula shown above.

Experimentals. Oxidative degradation of violanin and its deacylation product. Crystalline violanin chloride (5-10 mg) was dissolved in hot water $(1 \mathrm{ml})$, and after cooling $30 \%$ hydrogen peroxide $(1 \mathrm{ml})$ was added. The mixture was stood for several minutes at room temperature until the anthocyanin color had completely disappeared, and then neutralized with dilute aqueous sodium hydroxide. An excess of hydrogen peroxide remaining in solution was decomposed with platinum black by standing overnight at room temperature, filtered, and the colorless solution was evaporated to dryness in vacuo (at ca. $30^{\circ} \mathrm{C}$ ). A pale brown residue was dissolved in a mixture of water $(1 \mathrm{ml})$ and ethanol $(6 \mathrm{ml})$. The solution was saturated with anhydrous gaseous ammonia and kept at room temperature for two hours, where-

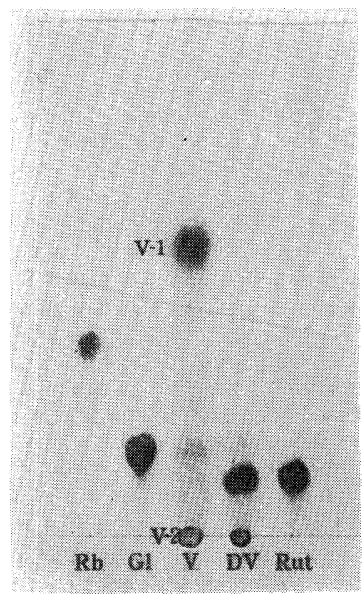

Fig. 1. Paper chromatogram of reducing substances obtained by oxidative degradation of violanin and its deacylated derivative. [Irrigated with $n-\mathrm{BuOH} / \mathrm{AcOH} / \mathrm{H}_{2} \mathrm{O}(4: 1: 5$, $\mathrm{v} / \mathrm{v}$ ) ; ascending, at ca. $20^{\circ} \mathrm{C}$ on Tôyô No. 51 filter paper. Developed by dipping in silver nitrate-sodium hydroxide reagent.]

$\mathrm{V}$ : degradation products of violanin DV: degradation products of deacylated violanin

Rh: L-rhamnose

Gl: D-glucose

Rut: rutinose (rhamnosyl-glucose)

by some brownish flocculent precipitates were formed. Without filtration, the whole solution was evaporated in vacuo, and the residue was dissolved in a small amount of water, and paper-chromatographed. In the case of deacylated violanin, similar treatment was made for the preparation of chromatograhic samples. The chromatographic irrigation was run with $n-\mathrm{BuOH} / \mathrm{AcOH} / \mathrm{H}_{2} \mathrm{O}(4: 1: 5, \mathrm{v} / \mathrm{v})$. The detection of the spots was made with fluorescence under UV-light on exposure to ammonia vapor. Among other fluorescent spots observed, violanin was characterized by the blue distinctive spot $(\mathrm{V}-1)$ at $\mathrm{Rf}$ $=0.52$. Besides, non-fluorescent, brown spot $(\mathrm{V}-2)$ was observed at the start. On the other hand, deacylated violanin gave two characteristic spots, namely $\mathrm{V}-2$ and another non-fluorescent spot, as shown in Fig. 1. By careful application of the sugar reagents for the latter before and after hydrolysis, it was proved that the non-fluorescent 
spot is nothing but rutinose, ${ }^{*)}$ i.e., 6-( $\beta$-1-L-rhamnosido)-D-glucose.

In order to determine the nature of $\mathrm{V}-1$, mass-paperchromatography was applied for the separation of this substance in quantity, using $n-\mathrm{BuOH} / \mathrm{AcOH} / \mathrm{H}_{2} \mathrm{O}(4: 1: 5, \mathrm{v} / \mathrm{v})$ for irrigation. Taking the fluorescence as a measure, V-1 band was carefully cut from the chromatogram, and eluted with $50 \%$ ethanol. After concentration in vacuo, this fraction gave only one spot on irrigation with various solvent mixtures ( $c f$., Table I). With this fraction, further analyses have been carried out as follows:

Acid hydrolysis of $V-1$. This fraction was hydrolyzed with $2 \mathrm{~N}$ sulfuric acid by boiling for two hours. After washing with ether, an aqueous solution was neutralized with barium hydroxide, filtered, and evaporated to dryness. The remaining product was extracted with $90 \%$ ethanol and paper-chromatographed. Two spots corresponding to D-glucose and L-rhamnose were clearly observed by color development with aniline hydrochloride and silver nitrate. $p$-Coumaric

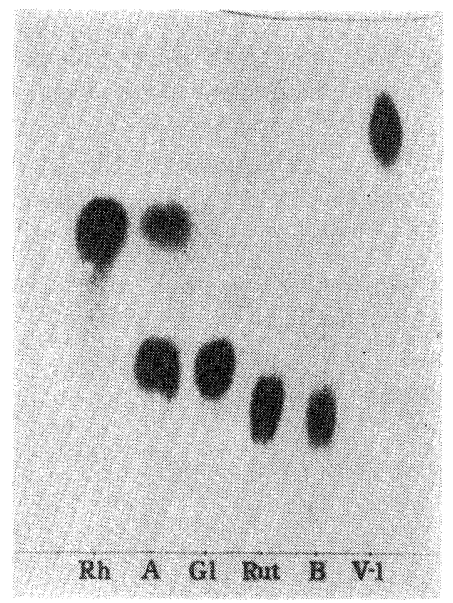

Fig. 2. Paper chromatogram of sugar components obtained from $\mathrm{V}-1$ by acid hydrolysis and deacylation. [Irrigated with $n$ - $\mathrm{BuOH} /$ pyridine $/ \mathrm{H}_{2} \mathrm{O} \quad(6: 3: 1, \mathrm{v} / \mathrm{v})$ by the ascending method, at ca. $20^{\circ} \mathrm{C}$, on Tôyô No. 51 filter paper. Developed by dipping in silver nitrate-sodium hydroxide reagent.]
A: acid hydrolysate of $\mathrm{V}-1$
B: deacylated V-1
Rh: L-rhamnose
$\mathrm{Gl}$ : D-glucose
Rut: rutinose (rhamnosyl-glucose)

Table I. Rf values of $\mathrm{V}-1, \mathrm{~V}-1^{\prime}$ and some products therefrom (by ascending method, on Tôyô No. 51 filter paper, at ca. $20^{\circ} \mathrm{C}$ )

\begin{tabular}{l|l|c|c|c|c|c|c|c|c}
\hline & $\mathrm{V}-1$ & $\begin{array}{c}\text { Deacy- } \\
\text { lated } \\
\mathrm{V}-1\end{array}$ & $\begin{array}{c}\text { Acid hydro- } \\
\text { lysates of } \\
\mathrm{V}-1\end{array}$ & $\mathrm{~V}-1^{\prime}$ & $\begin{array}{c}\text { Deacy- } \\
\text { lated } \\
\mathrm{V}-1^{\prime}\end{array}$ & $\begin{array}{c}\text { Sugar } \\
\text { of } \\
\mathrm{V}-2\end{array}$ & $\begin{array}{c}\text { Glu- } \\
\text { cose }\end{array}$ & $\begin{array}{c}\text { Rham- } \\
\text { nose }\end{array}$ & $\begin{array}{c}\text { Ruti- } \\
\text { nose }\end{array}$ \\
\hline $\begin{array}{c}\text { Ethyl acetate/ } \\
\text { pyridine/H2 } \\
\begin{array}{c}(120: 50: 40, \mathrm{v} / \mathrm{v}) \\
n-\mathrm{BuOH} / \mathrm{pyridine} \\
\mathrm{H}_{2} \mathrm{O}\end{array}\end{array}$ & 0.84 & 0.25 & $\left\{\begin{array}{l}0.55 \\
0.31\end{array}\right.$ & 0.96 & 0.55 & 0.31 & 0.31 & 0.54 & 0.25 \\
$\begin{array}{c}(6: 3: 1, \mathrm{v} / \mathrm{v}) \\
n-\mathrm{BuOH} / \mathrm{AcOH} / \\
\mathrm{H}_{2} \mathrm{O} \\
(4: 1: 5, \mathrm{v} / \mathrm{v})\end{array}$ & 0.58 & 0.15 & $\left\{\begin{array}{l}0.20 \\
0.44\end{array}\right.$ & 0.87 & 0.43 & 0.20 & 0.20 & 0.44 & 0.16 \\
\hline
\end{tabular}

*) Enzymatically prepared from rutin by Dr. H. Suzuki in this Institute. 
acid was detected from the ethereal fraction obtained above (Fig. 2, Tables I and II).

Table II. Rf data available for the identification of $p$-coumaric acid liberated from V-1 and V-1'

(by ascending method, on Tôyô No. 51 filter paper, at ca. $20^{\circ} \mathrm{C}$ )

\begin{tabular}{|c|c|c|c|c|c|}
\hline & $\begin{array}{c}\text { Acid } \\
\text { from } \\
\text { V-1 }\end{array}$ & $\begin{array}{l}\text { Acid } \\
\text { from } \\
\text { V-1' }\end{array}$ & $\begin{array}{l}\text { Authentic } \\
p \text {-coumaric } \\
\text { acid }\end{array}$ & $\mathrm{V}-1$ & $\mathrm{~V}-1^{\prime}$ \\
\hline $\begin{array}{l}\mathrm{C}_{6} \mathrm{H}_{6} / \mathrm{AcOH} / \mathrm{H}_{2} \mathrm{O} \\
(125: 72: 3, \mathrm{v} / \mathrm{v})\end{array}$ & 0.86 & 0.86 & 0.87 & 0.12 & 0.80 \\
\hline $\begin{array}{l}\text { iso- } \mathrm{PrOH} / \mathrm{NH}_{4} \mathrm{OH} / \mathrm{H}_{2} \mathrm{O} \\
(8: 1: 1, \mathrm{v} / \mathrm{v})\end{array}$ & 0.20 & 0.20 & 0.20 & 0.23 & 0.47 \\
\hline $\begin{array}{l}n-\mathrm{BuOH} / \text { pyridine } / \mathrm{H}_{2} \mathrm{O} \\
(140: 30: 30, \mathrm{v} / \mathrm{v})\end{array}$ & 0.67 & 0.67 & 0.68 & 0.52 & 0.79 \\
\hline $\begin{array}{c}n-\mathrm{BuOH} / \mathrm{AcOH} / \mathrm{H}_{2} \mathrm{O} \\
(4: 1: 5, \mathrm{v} / \mathrm{v})\end{array}$ & 0.86 & 0.86 & 0.86 & 0.50 & 0.78 \\
\hline $\begin{array}{l}\text { Reaction of the spots with } \\
\text { diazotized sulfanilic acid }\end{array}$ & $\mathrm{r}$ & red & red & red & red \\
\hline Fluorescence in $\mathrm{NH}_{3}$-gas & purple & purple & purple & blue & blue \\
\hline
\end{tabular}

Deacylation of $V-1$. The fraction $V-1$ was treated with $8 \%$ aqueous sodium hydroxide in an atmosphere of nitrogen for 30 minutes at room temperature. The reaction mixture was adjusted to $\mathrm{pH} 3$ with dilute hydrochloric acid, washed twice with ether, and evaporated to dryness. The residue was dissolved in a small amount of ethanol and filtered free from insoluble salt. Paper-chromatographic tests have shown that this solution contains rutinose alone, as can be seen from Fig. 2 and Table I. On the other hand, $p$-coumaric acid was detected only in an ethereal layer (Table II). From these observations, it becomes evident that $\mathrm{V}-1$ is a $p$-coumaric ester of rhamnosylglucose, which is liberated from the 3-position of delphinidin.

Partial hydrolysis of $V-1$. This experiment was carried out in order to determine the sequence of $p$-coumaric acid and sugars. For this purpose, V-1 was subjected to mild hydrolysis by dissolving in $1 \mathrm{~N}$ hydrochloric acid and heating on a water bath at $70^{\circ} \mathrm{C}$ for five hours. At definite intervals, small aliquots were taken from the reaction mixture and spotted side by side on a large sheet of chromatographic paper. The irrigation was run with $n-\mathrm{BuOH} / \mathrm{AcOH} / \mathrm{H}_{2} \mathrm{O}(4: 1$ : $5, \mathrm{v} / \mathrm{v})$. The chromatogram obtained has revealed that one intermediary spot showing $\mathrm{Rf}=0.81\left(\mathrm{~V}-\mathrm{1}^{\prime}\right)$ was produced during hydrolysis, whose fluorescence and color reaction were quite similar to those of $\mathrm{V}-1$.

For further analysis of this product, $\mathrm{V}-\mathbf{1}^{\prime}$ fraction was prepared by means of mass paper chromatography in a similar manner as mentioned above. This fraction was purified by repeated chromatography 
until it showed a single spot on the paper chromatogram after development with aniline hydrochloride or diazotized sulfanilic acid ( $c f$., Table I). The product $\left(\mathrm{V}-1^{\prime}\right)$ thus prepared was subjected to saponification test in the same way as described above in the case of V-1. The results are summarized in Table I and II, from which it is concluded that $p$-coumaric acid is linked with L-rhamnose but not with D-glucose.

Acid hydrolysis of $V-2$. According to Karrer and de Meuron, ${ }^{3)}$ sugar residue attached to the 5-hydroxyl of anthocyanidin is not liberated on peroxide degradation, but retained in a brownish product which is almost insoluble in ethanol. Therefore, the brown spot V-2

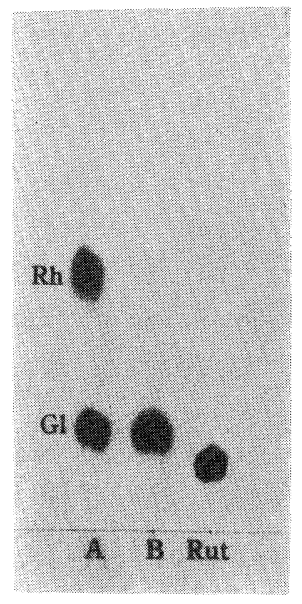

Fig. 3. Paper chromatogram for the identification of the sugar component obtained by acid hydrolysis of $\mathrm{V}-2$. [Developed with $n-\mathrm{BuOH} / \mathrm{AcOH} / \mathrm{H}_{2} \mathrm{O}(4: 1: 5, \mathrm{v} / \mathrm{v})$ ascending, at ca. $20^{\circ} \mathrm{C}$ on Tôyô No. 51 filter paper. Visualized with silver nitrate-sodium hydroxide dipping reagent.]

A: mixture of $\mathrm{D}$-glucose $(\mathrm{Gl})$ and L-rhamnose $(\mathrm{Rh})$

B: sugar obtained from $\mathrm{V}-2$

Rut: rutinose

remaining at the start on the chromatogram was eluted with warm water, and hydrolyzed with $2 \mathrm{~N}$ sulfuric acid. With this hydrolysate, some tests for sugar component were made by chromatographic means as usual. Only D-gluose could be detected in this case, as seen from Fig. 3 and Table I.

The authors express their sincere thanks to Emer. Prof. Y. Shibata for his valuable suggestion and guidance throughout this work. Thanks are also due to Dr. H. Suzuki in this Institute for his kind supply of rutinose.

\section{References}

1) K. Takeda, Y. Abe and K. Hayashi: Proc. Japan Acad., 39, 225 (1963).

2) K. Takeda and K. Hayashi: Bot. Mag. Tokyo, 76, 206 (1963).

3) P. Karrer and G. de Meuron: Helv. Chim. Acta, 15, 1212 (1932). 